\title{
Study on the Sound Field Distribution in the Intercity High-Speed Railway Coaches
}

\author{
Weijie Bai ${ }^{1}$, Liu Yan ${ }^{1}$, Xiaopai Zhang ${ }^{1}$, Xiaojuan Zhang ${ }^{2}$ and Changbin Zhang ${ }^{3}$ \\ ${ }^{1}$ College of Transportation Engineering, Dalian Jiaotong University, Dalian China \\ ${ }^{2}$ Department of Mechanical Engineering, Dalian Institute of Science and Technology, Dalian China \\ ${ }^{3}$ Department of Educational Administration, Dalian Jiaotong University, Dalian China
}

\begin{abstract}
The noise measurement and analysis system of multi-channel was used at a test of high-speed intercity railway coaches analyzing the noise at different operating conditions and different speed, the sound field distribution in the intercity high-speed railway coach was tested and analyzed. The results show that the maximum noise in the car of the same height which is at different positions is at the vestibule diaphragm, followed by the bogie positions at the end portion of the vehicle body, minimizing noise is at the vehicle center position, the noise value at the vestibule diaphragm and the central body was maximum difference $20 \mathrm{~dB}(\mathrm{~A})$; the noise inside the car reflected by the tunnel wall is mainly in the frequency range $630-1000 \mathrm{~Hz}$; in the same location of different heights, noise is concentrated in the low and middle frequency band, and in that band noise attenuation is slow, the noise is mainly through the floor and the roof spreading to the car; it is obtained that the noise frequency of the intercity high-speed railway passenger car is mainly concentrated in $100-1000 \mathrm{~Hz}$.
\end{abstract}

Keywords-acoustics; intercity train; interior noise; measurement; distribution regularities

\section{CONTENT OF THE INTERIOR NOISE TEST}

The interior noise test of the intercity high-speed railway coach is on the basis of national standard[1]"GB/T 12816-2006 The limiting value and measurement method for the interior noise in the railway passenger coach," and the noisy positions[2]. And we arrange 11 measurement points, the position description is shown in Figure 1 and the distribution of each point is shown in Table 1 . This test includes the railway coach in different working conditions such as the coach through the tunnel, the emergency brake and in flat road, the noise level of each test point inside the car is tested under different speed such as $160 \mathrm{~km} / \mathrm{h}, 200 \mathrm{~km} / \mathrm{h}, 250 \mathrm{~km} / \mathrm{h}$. The multi-channel noise measurement and analysis system is used and it can simultaneously test the noise level at different locations. Subsequently, the measured data is replayed and compared, the magnitude and variation of noise in different positions, at different speed and in different working conditions is concluded.

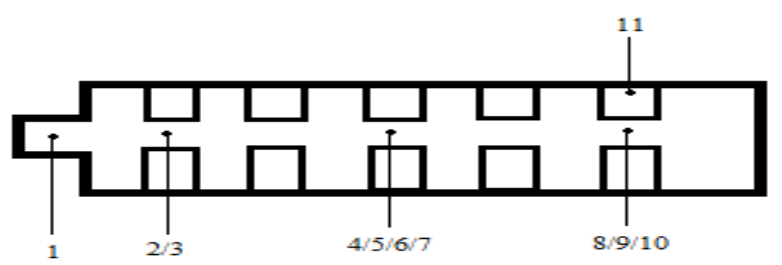

FIGURE I. NOISE MEASUREMENT LOCATIONS
TABLE I. THE DISTRIBUTION OF THE NOISE TEST POINTS

\begin{tabular}{|c|c|}
\hline Test points & Location \\
\hline Mic01 & Vestibule diaphragm and $1.6 \mathrm{~m}$ height \\
\hline Mic02 & No.1 bogie and $1.2 \mathrm{~m}$ height \\
\hline Mic03 & No.1 bogie and $1.6 \mathrm{~m}$ height \\
\hline Mic04 & Center position and $0.15 \mathrm{~m}$ height \\
\hline Mic05 & Center position and $1.2 \mathrm{~m}$ height \\
\hline Mic06 & Center position and $1.6 \mathrm{~m}$ height \\
\hline Mic07 & Center position $0.15 \mathrm{~m}$ below the roof \\
\hline Mic08 & No.2 bogie and $0.15 \mathrm{~m}$ height \\
\hline Mic09 & No.2 bogie and $1.2 \mathrm{~m}$ height \\
\hline Mic10 & No.2 bogie and $1.6 \mathrm{~m}$ height \\
\hline Mic11 & $\begin{array}{r}\text { The window position above No.2 bogie } \\
\text { and } 1.2 \mathrm{~m} \text { height }\end{array}$ \\
\hline
\end{tabular}

\section{RESUlts AND ANALYSIS OF NOISE TEST}

A. Noise Measurement and Analysis of the Same Height in Different Positions

In order to obtain the noise variation at different positions in the coach, the noise value of the two bogies and the center position that was $1.2 \mathrm{~m}$ above the floor was simultaneously tested at $200 \mathrm{~km} / \mathrm{h}$ speed in the open air and tunnels, when the noise level was measured at $1.6 \mathrm{~m}$, the center of the vestibule diaphragm was added a measuring point at the height of $1.6 \mathrm{~m}$ from the ferry board. Data for each measuring point was analyzed with A-weighted and 1/3 octave, the A-weighted and $1 / 3$ octave spectrum of the noise value in different positions interior the coach which runs in different working conditions at $200 \mathrm{~km} / \mathrm{h}$ is showed in Figure 2 - Figure 3.

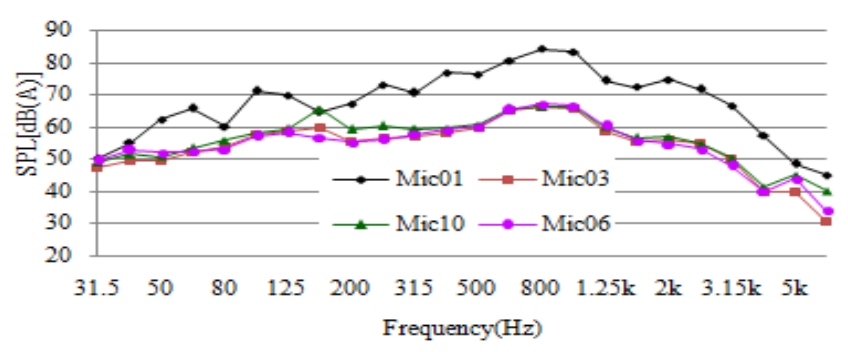

FIGURE II. ONE-THIRD TIMES FREQUENCY NOISEVALUE OF 1.6M ABOVE THE FLOOR WHEN CROSSING THE TUNNEL 


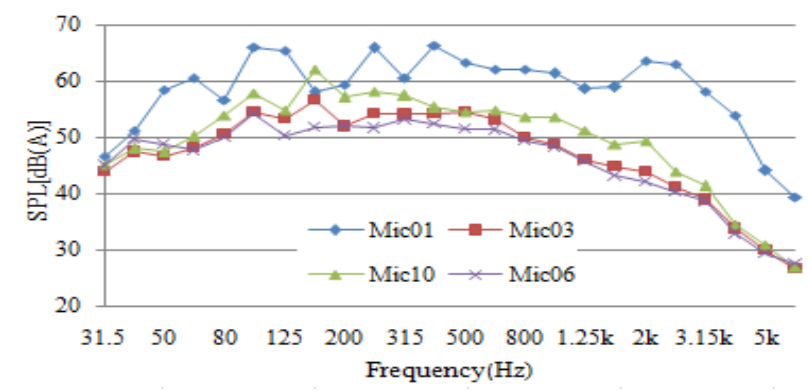

FIGURE III. ONE-THIRD TIMES FREQUENCY NOISE VALUE OF 1.6M ABOVE THE FLOOR WHEN RUNNING IN OPEN AIR

As the trend of the curve that Figure 2-Figure 3 shows, the curve of these noise measuring points has the similar trend except the windshield central measuring point. It indicates that distribution of sound field inside the vehicle at different locations has the consistency distribution within the band. Regardless of the intercity trains running in the tunnel or open air, the minimum noise value of the tested four points (bogie 1 , bogie 2, the central body and windshield center $1.6 \mathrm{~m}$ from the ground),is at the central body, followed by $1.6 \mathrm{~m}$ above the floor of bogie 1 and the bogies 2, the largest noise is at the windshield central location which is $1.6 \mathrm{~m}$ from the crossing plate, the reason is the windshield is received radiation noise by each vibration source, as well as the sound leakage caused by the weak sealing performance of the windshield. The noise value of bogie 2 is relatively higher than bogie 1 because it is closer to the vehicle's pantograph and air conditioner. The noise value at the same test position of the vehicle working in different conditions is maximum difference $20 \mathrm{~dB}$ (A), In the open air and tunnel conditions, the noise level at the windshield is significantly higher than the noise level of the other measuring points, the largest difference reaches more than $20 \mathrm{~dB}(\mathrm{~A})$, indicating that the windshield is the weak link at the interior noise control.

Comparing Figure 4 and Figure 5 trains running in the tunnel and open air line, while in the tunnel, the noise curve peak at about $800 \mathrm{~Hz}$, and the noise in $630-1000 \mathrm{~Hz}$ is significantly higher than the noise level at other frequencies, it shows the tunnel's impact to the interior sound field mainly concentrates in more than $400 \mathrm{~Hz}$, especially in the range $630-1000 \mathrm{~Hz}$. Comparing the same frequency band of the open air line, the noise inside the vehicle reflecting by the tunnel wall is mainly concentrated in $630-1000 \mathrm{~Hz}$ frequency range while the train through the tunnel, thereby causing the peak in the spectrum.

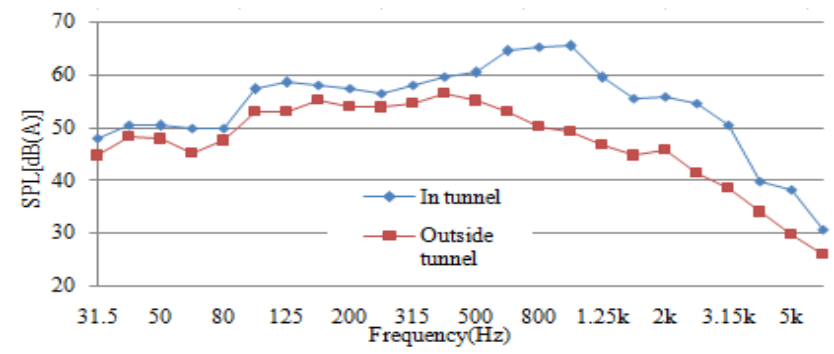

FIGURE IV. ONE-THIRD TIMES FREQUENCY NOISE VALUE OF 1.2M ABOVE THE FLOOR AT THE BOGIE 1 IN DIFFERENT WORKING CONDITIONS

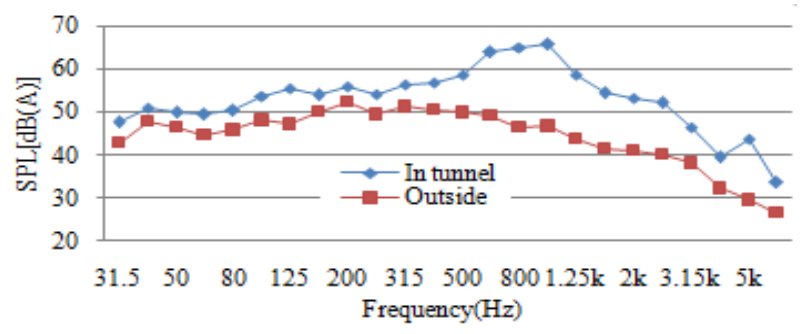

FIGURE V. ONE-THIRD TIMES FREQUENCY NOISE VALUE OF 1.2M ABOVE THE FLOOR AT THE VEHICLE CENTRE IN DIFFERENT WORKING CONDITIONS

B. Noise Measurement and Analysis of Different Height in the Same Positions

The experiment simultaneously tested the noise value of the vehicle center at the height of $0.15 \mathrm{~m}, 1.2 \mathrm{~m}, 1.6 \mathrm{~m}$ from the floor, and $0.15 \mathrm{~m}$ below the roof, the test results shows in Figure 6-Figure 8.

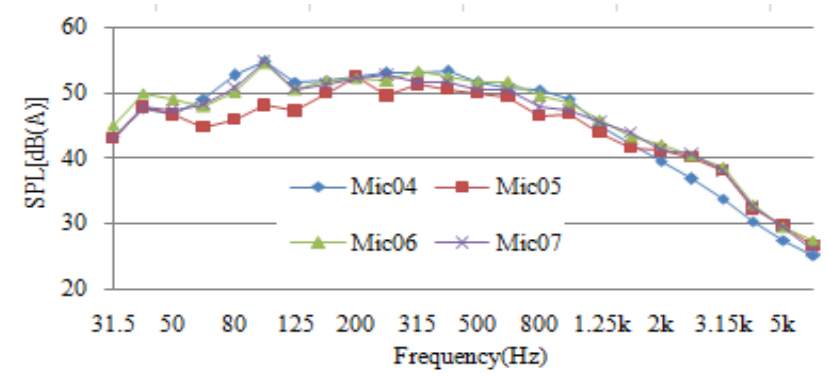

FIGURE VI. ONE-THIRD TIMES FREQUENCY NOISE VALUE IN DIFFERENT HEIGHT OF THE VEHICLE CENTRE AT THE SPEED OF $200 \mathrm{KM} / \mathrm{H}$

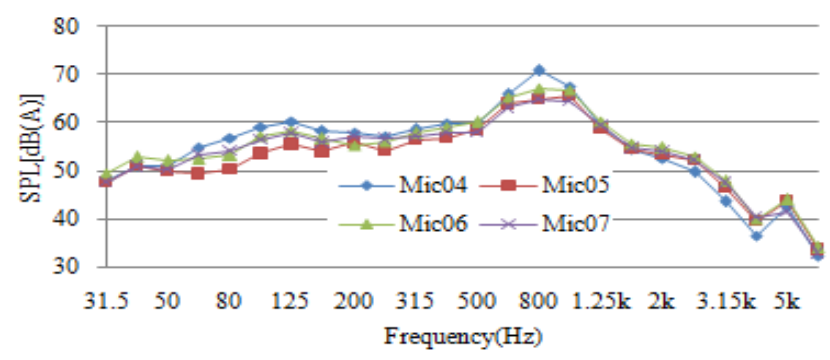

FIGURE VII. ONE-THIRD TIMES FREQUENCY NOISE VALUE IN DIFFERENT HEIGHT OF THE VEHICLE CENTRE WHEN RUNNING IN TUNNEL

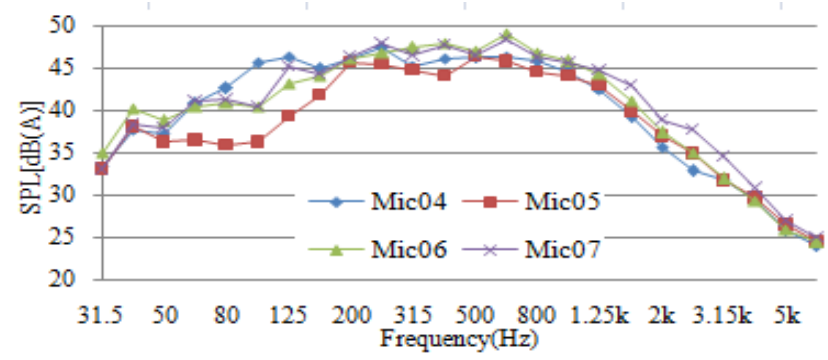

FIGURE VIII. ONE-THIRD TIMES FREQUENCY NOISE VALUE IN DIFFERENT HEIGHT OF THE VEHICLE CENTRE WHEN BRAKING 
It can be analyzed in Figure 6 to Figure 8 that the distribution of the noise value measured performs large bandwidth, but the noise energy mainly concentrates in the low frequency region. The curve of four noise measuring points at different heights of the same position substantially shows the same trend no matter what working conditions, it indicates that the distribution of interior noise in the frequency doesn't change significantly with height. In the three working conditions, the maximum noise is at the floor, followed by the roof and the position that is $1.6 \mathrm{~m}$ above the floor, the minimum noise values is the position $1.2 \mathrm{~m}$ from the floor .It can be seen that the noise which comes from the floor and roof is greater than the sidewall, so the floor and roof is the main afferent pathway of the interior noise. The noise energy of different heights is concentrated in $160-1000 \mathrm{~Hz}$, low and middle frequencies band, and it slowly decayed.

\section{Noise Measurement and Analysis at Different Speed}

As Figure 9-Figure 11 shows, the noise value (the window above the bogie 2,1.2m above the floor at the vehicle center and the bogie 1) was tested while the train was running in the flat road at $160 \mathrm{~km} / \mathrm{h}, 200 \mathrm{~km} / \mathrm{h}, 250 \mathrm{~km} / \mathrm{h}$. The figure shows that, with the increasing of the speed, the noise in the same measuring point was continuously improved. The interior sound pressure level of the train at $200 \mathrm{~km} / \mathrm{h}$ was increased about $10 \mathrm{~dB}(\mathrm{~A})$ than the noise at $160 \mathrm{~km} / \mathrm{h}$, and at $250 \mathrm{~km} / \mathrm{h}$ the sound pressure level was increased approximately $9 \mathrm{~dB}(\mathrm{~A})$ than the noise at $200 \mathrm{~km} / \mathrm{h}$. Although the noise performed large broadband distribution, the noise values at different speeds and different frequency varied widely. Interior noise source analysis shows that EMU interior noise has a variety of sources, but with the increasing of speed only the wheel-rail noise, the aerodynamic noise and secondary noise generated by their excitation[3] had significant increase ,so a large part of these increase amount of noise was generated from the above three noise sources. It can be seen from the noise curve trend that the trend curves of the noise measurement points have the same shape and the increase of the train speed didn't change the frequency distribution characteristics of the interior noise.

Table 2 shows the maximum noise at 1/3 octave center frequency of the measurement points that the high-speed railway passenger coach worked in two conditions (open air and tunnel) and at different speed .And the noise of the windshield center $1.6 \mathrm{~m}$ from the ground, $1.6 \mathrm{~m}$ above the floor of bogie 1 , the central body $1.6 \mathrm{~m}$ above the floor, the window above the bogie 2 which is $1.2 \mathrm{~m}$ from the floor was tested. It can be seen from the table the maximum noise appear within $100-1000 \mathrm{~Hz}$ frequency range, which indicated that the main frequency range which noise occurred in the measuring EMU was within that frequency range, and it should be attracted enough attention.

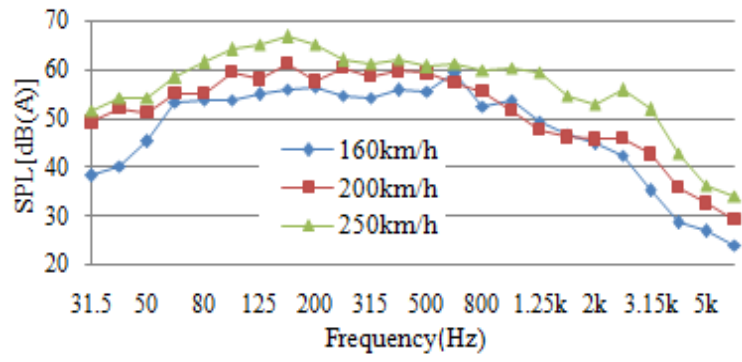

FIGURE IX. ONE-THIRD TIMES FREQUENCY NOISE VALUE IN THE HEIGHT OF 1.2M AT THE WINDOW POSITION ABOVE THE BOGIE 2 AT DIFFERENT SPEED

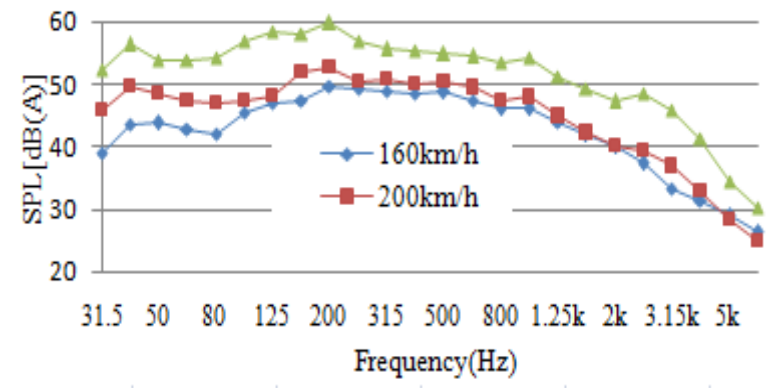

FIGURE X. ONE-THIRD TIMES FREQUENCY NOISE VALUE IN THE HEIGHT OF 1.2M ABOVE THE FLOOR AT THE VEHICLE CENTRE AT DIFFERENT SPEED

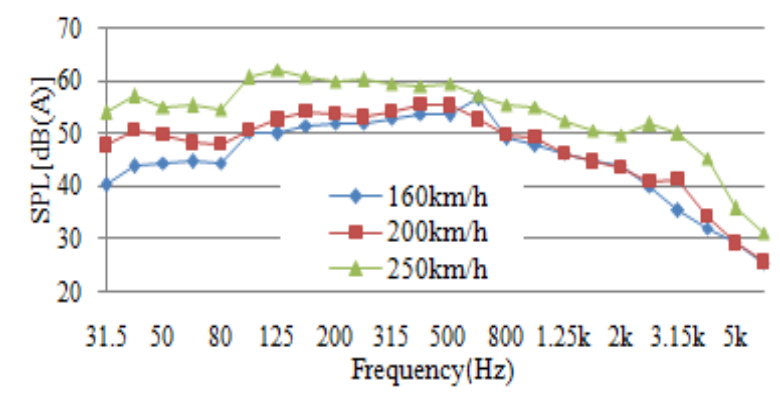

FIGURE XI. ONE-THIRD TIMES FREQUENCY NOISE VALUE IN THE HEIGHT OF 1.2M ABOVE THE FLOOR AT THE BOGIE 1 AT DIFFERENT SPEED

TABLE II. THE CENTER FREQUENCY(Hz) OF THE MAXIMUM NOISE VALUE AT DIFFERENT SPEED

\begin{tabular}{|c|c|c|c|c|}
\hline Points & Mic01 & Mic02 & Mic06 & Mic11 \\
Condition & 800 & 1000 & 1000 & 1000 \\
\hline $\begin{array}{c}200 \mathrm{~km} / \mathrm{h}, \\
\text { tunnel }\end{array}$ & 400 & 250 & 100 & 400 \\
\hline $\begin{array}{c}230 \mathrm{~km} / \mathrm{h}, \\
\text { tunnel }\end{array}$ & 250 & 315 & 100 & 160 \\
\hline $\begin{array}{c}250 \mathrm{~km} / \mathrm{h}, \\
\text { tunnel }\end{array}$ & 630 & 630 & 630 & 630 \\
\hline $\begin{array}{c}160 \mathrm{~km} / \mathrm{h}, \\
\text { tunnel }\end{array}$ & 200 & 400 & 200 & 200 \\
\hline $\begin{array}{c}200 \mathrm{~km} / \mathrm{h}, \\
\text { tunnel }\end{array}$ & 125 & 160 & 125 & 160 \\
\hline $\begin{array}{c}250 \mathrm{~km} / \mathrm{h}, \\
\text { tunnel }\end{array}$ & & & & \\
\hline
\end{tabular}




\section{CONCLUSION}

a) At the same height but different locations in the car, the maximum interior noise of the high-speed railway car is at the vestibule diaphragm, followed by the bogie above the end portion of the vehicle body, and the minimum noise is at the vehicle center position. The noise inside the car reflected by the tunnel wall is mainly in the frequency range $630-1000 \mathrm{~Hz}$;

b) At the same location but different height inside the car , the interior noise of the high speed passenger train mainly concentrates in $160-1000 \mathrm{~Hz}$, and in that low frequency band, noise attenuates slowly; the floor and the roof of the train are the main afferent pathway ;

c) The noise of the high-speed railway passenger car increases with the increase of speed, but the speed does not affect the spectral characteristics of interior noise. The noise of the intercity high-speed railway passenger car frequency band is $100-1000 \mathrm{~Hz}$.

\section{REFERENCE}

[1] National Standard. "GB/T 12816-2006 The limiting value and measurement method for the interior noise in the railway passenger coach"[S]. 2006.

[2] Zhihua Luo."Internal Noise Control of Passenger Train"[J] the China Science and Technology Information, 2006, 5.

[3] Yujun Bao, Cong Li, Hong Yang."EMU Noise Sources and Transfer Path Analysis"[J] Railway Technical Supervision, 2014. 